\title{
Effects of Door Width and Human Body Size on Walking Speed
}

\author{
Siwalee Jetthumrong and Phairoat Ladavichitkul \\ Industrial Engineering Department, Faculty of Engineering, Chulalongkorn University, Bangkok, Thailand
}

\begin{abstract}
Door width is one of the important factors to concern in layout or facilities design because it affects directly to traffic speed and overall traffic time simultaneously. Nowadays, common assessment method is computer simulation which is still not realistic due to the unchanged speed of model while walking through a door. This research aims to study an effect of door width to individual walking speed. Sixty subjects participated in the experiment and performed task by walking through the door that is set the width as 40, 50, 60, 70, 80, 90 and 100 centimetres. The optical motion capture system was used to determine walking speed. The results showed that Fitts' law was applied to the participants with high weight. Door width below 70 centimetres significantly affected to changing speed at $0-0.5 \mathrm{~m}$. before the door. Additionally, human size also affected changing speed. The factors include shoulder breadth, weight and interaction between shoulder breadth and weight were found to be significant. These factors explained $54.2 \%$ of changing speed.
\end{abstract}

\section{Introduction}

In places and buildings usability, passageway width is one of the important factors to be considered because it affects to overall traffic time. As we know that time is a valuable resource. In the city, people usually travel hurriedly but the problem of overcrowded people in public area is very common. Especially at the rush hours in some public places such as subway stations or even airports, amount of passengers decrease extremely but the traffic area is restrict. This may cause retardation in pedestrian traffic. As a result, it causes late in transportation that may affect to various issues such as society or economics. Moreover, passageway width becomes a critical factor in case of emergency because traffic time represents the evacuation time. If the traffic area especially the exit is not wide enough, it cannot support evacuation of all people lead to injuries and losses. Thus, an assessment of passageway width in public place is required when the situations change. If the impropriety between amount of people and traffic area is indicated, this will lead to further solutions.

There are two common assessment methods including hand calculation and computer simulation. Hand calculation usually follows the equations defined by National Fire Protection Association Handbook [1]. The equations treat the occupants as fluid particles which their individual speed depends on the density of the area.

$$
S=K-0.266 K D
$$

When $\mathrm{S}$ is the walking speed throughout the line, $\mathrm{K}$ is the velocity factor which depends on egress components such as corridor or stairway. D is the density of the area in person $/ \mathrm{m}^{2}$.
Computer simulation program, which is widely used to support layout and facilities design, will simulate occupant's behaviour and finally calculate the overall egress time. However, the movement of human model is still not realistic. The walking speed of the model will decrease only when the density of the area becomes higher [2].

In fact, human have a complex cognitive process called perception. When human perceive that they are approaching to the narrower area such as a door, they will automatically decrease their walking speed in order to make sure they are able to control themselves. In other words, door width has an influence on human walking speed. This follows the concept of the speed and accuracy trade-off theory which describes human's performance in both physical and cognitive task. According to Fitts' law [3], the movement time from target to target increases by the difficulty of the task which depends on target width and target amplitude. Similarly, narrower door should cause more speed reduction. The accuracy is needed to maintain safety so walking speed should decrease by target width which refers to door width.

Generally, human walking speed depends on both physical factors such as age, height [4], weight or body proportions and psychological factors include emotion or even personality type. Moreover, walking through the door is also related to motor control ability which is affected from various factors such as age, fatigue, or gender. Men are likely to response faster [5], combine with the risk-taking behaviour of women that lower than men [6].

If the effect of door width on walking speed can be identified, the actual walking speed can be predicted. This will lead to more accuracy in pedestrian simulation. Human characteristics which can affect walking speed include 
gender, weight, height and body width are also considered in this experiment.

\section{Method}

\subsection{Participants}

Sixty college students (33 males and 27 females) participated in this experiment. Age range was 20-29 $(21.98 \pm 2.03$ years $)$. All participants were healthy and did not have any medical records in hip and knees. Body strength was normal, not athlete. Normal sights or wore glasses/contact lens through the experiment.

\subsection{Apparatus}

Martin-type anthropometer was used for measuring body proportions of all participants. In order to determine walking speed, OptiTrack motion capture system was used for collecting data at sampling rate of 50 frames per second (fps). The system consisted of twelve OptiTrack FLEX 13 cameras and tracking software, Motive:Body version 1.7.5 (NaturalPoint, Inc., Corvallis, OR). The capture area was 4.5 metres x 3.9 metres, completely covered by non-slip mat.

\subsection{Procedure}

\subsubsection{Experimental setup}

First, the system was set in the Human Factors and Ergonomics laboratory, Chulalongkorn University. Before the experiment each day, system calibration was performed. The calibration procedure consisted of wanding the entire capture volume and setting ground plane. The mean error of calibration was needed to be around one millimetre, otherwise the calibration process should be repeated.

The door was formed within the capture area by two rigid rectangle Polypropylene-corrugated boards with 22 centimetres width and 1.9 metres height. Each board had reflective markers (diameter $=14 \mathrm{~mm}$.) on it as the reference. Seven different door widths were considered in this experiment: 40, 50, 60, 70, 80, 90 and 100 centimetres. For each reconfiguration, the width was measured by measuring tape and would be accepted if the difference from desired width was not exceed five millimetres.

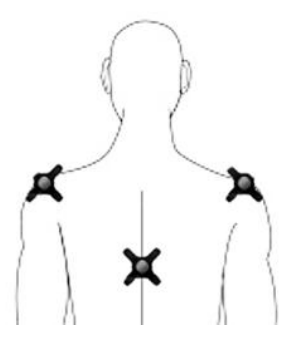

Figure 1. Position of markers.

The following anthropometric data of all participants were measured: weight, height, shoulder breadth and hip breadth. Height was a stature from top of the head to floor. Shoulder breadth was the width between left and right acromion. Hip breadth was the width between left and right pelvis. After the measurement, each participant wore t-shirt or tight-fitting clothes. Three reflective markers were attached on participants' body using velcro tape as shown in Figure 1.

\subsubsection{Data collecting}

The task was walking through the door. All participants were briefed to walk as fast as they can but did not think of emergency situation. Each participant performed the task one by one in random sequence of door width. At the beginning of each task, the participant stood at start point which was three metres away from capture area. All tasks were captured by motion capture system since participants appeared in the capture area until they walked through the door. The total distance was 6.9 meters: 5.5 meters before the door and 1.4 meter after the door (see Figure 2).

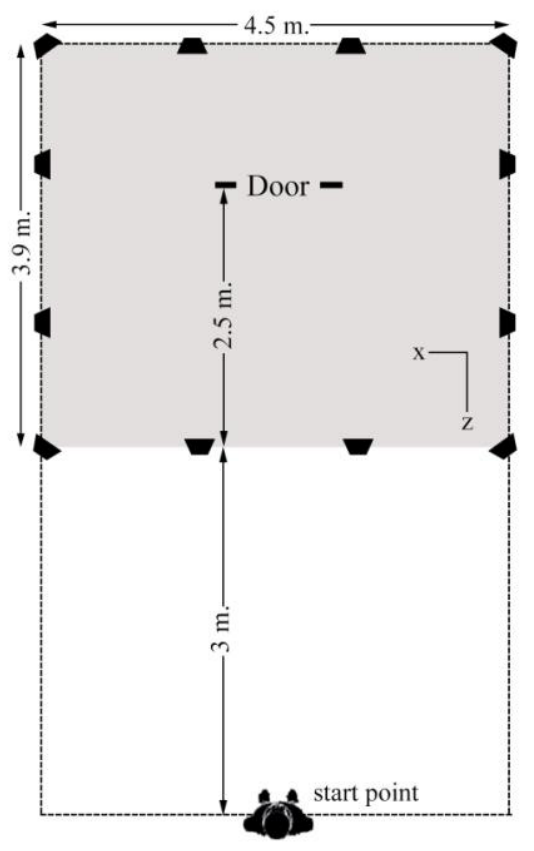

Figure 2. Experimental layout.

Data verifying was carried out right after each trial in order to prove that participant's body did not hit the door. If the markers on the boards moved from their positions more than five millimetres, that trial would be rejected. The repetition would not exceed three times in order to avoid learning-by-doing behavior.

The results consisted of :

60 Participants $\times$

7 Conditions of door width $€\{40 \mathrm{~cm} ., 50 \mathrm{~cm} ., 60 \mathrm{~cm} ., 70$ cm., $80 \mathrm{~cm} ., 90 \mathrm{~cm} ., 100 \mathrm{~cm}$.

$=420$ trials

\subsubsection{Data processing}

After the experiment, all data obtained would be processed and manually calculated to walking speed in the walking direction. Since the data is 3D positions of markers, walking speed in $\mathrm{z}$-axis was; 


$$
v_{i}=\left(z_{i+1}-z_{i-1}\right) /\left(t_{i+1}-t_{i-1}\right)
$$

When $v_{i}$ is an instantaneous speed at frame $\mathrm{i}, z_{i+1}$ and $z_{i-1}$ are positions in $\mathrm{z}$-axis at frame $\mathrm{i}+1$ and $\mathrm{i}-1$, respectively. $t_{i+1}$ and $t_{i-1}$ are time at frame $\mathrm{i}+1$ and $\mathrm{i}-1$, respectively.

Changing speed at specific distance was provided by the difference of initial speed and terminal speed. In order to normalize value, changing speed was then divided by initial speed.

$$
\Delta v=\left(v_{1}-v_{0}\right) / v_{0}
$$

When $v_{l}$ is the terminal speed and $v_{0}$ is the initial speed.

\subsection{Variables}

In this study, the dependent variable is changing speed $(\Delta v)$. The independent variables considered in this experiment were divided into two groups. First group is the factor of passageway, which is door width. Second group is human characteristics which consists of gender, weight, height and body width that includes shoulder breadth and hip breadth.

\section{Results and Discussion}

The results are presented as walking speed versus distance before the door. It is found that walking speed of all participants is not constant along the distance. The trend is likely to decrease when participants approach to the door. It clearly shows that the door has an effect on participants' response. In addition, the distance before the door is divided to 4 intervals as $1.5-2 \mathrm{~m} ., 1-1.5 \mathrm{~m}$., $0.5-1 \mathrm{~m}$. and $0-0.5 \mathrm{~m}$. It is found that the speed change or slope at $0-0.5 \mathrm{~m}$. is the lowest and also has the highest variance. Hence, most participants reduced their walking speed at $0.5 \mathrm{~m}$. before the door.

After data cleaning and excluding the outliers, all participants are divided to three groups as follows.

I. Walking speed declines with door width at $0.5 \mathrm{~m}$. before the door.

II. Walking speed slightly declines with door width since $2 \mathrm{~m}$. before the door.

III. Walking speed does not decline with door width.

Table 1. Participants characteristics, according to groups.

\begin{tabular}{|c|c|c|c|}
\hline $\begin{array}{c}\text { Shoulder } \\
\text { breadth } \\
\text { (cm.) }\end{array}$ & $41.35 \pm 2.79$ & $40.42 \pm 3.31$ & $39.43 \pm 3.70$ \\
\hline $\begin{array}{c}\text { Hip breadth } \\
\text { (cm.) }\end{array}$ & $32.41 \pm 3.44$ & $29.71 \pm 3.60$ & $32.17 \pm 5.03$ \\
\hline $\begin{array}{c}\text { Height } \\
\text { (cm.) }\end{array}$ & $167.70 \pm 6.57$ & $168.39 \pm 8.76$ & $164.75 \pm 10.06$ \\
\hline $\begin{array}{c}* \text { Weight } \\
\text { (kg.) }\end{array}$ & $68.33 \pm 9.83$ & $60.45 \pm 10.91$ & $57.70 \pm 11.75$ \\
\hline
\end{tabular}

Results are reported in mean $\pm \mathrm{SD}$.

*Significantly different among groups $(\mathrm{p}<0.05)$
General characteristics of participants are shown in Table 1. It is found that weight is significantly different among groups. Participants in group I have higher weight compared with group II and III. In this paper, group I will be considered afterwards since the walking speed is mainly influenced by door width. Twelve participants (20\% of all participants) are classified into group I (eight males and four females).

\subsection{Walking behaviour}

As Figure 3 illustrates, walking speed of participants fluctuate at $0.5-2 \mathrm{~m}$. before the door then hardly reduce at $0.5 \mathrm{~m}$. This obviously occurs at the narrow door, around 40$60 \mathrm{~cm}$. For the door width of $70 \mathrm{~cm}$. upwards, the graphs appear to be flat along the distance. This implies the constant walking speed when the door is wide enough. This corresponds with minimum standard door width of $81.3 \mathrm{~cm}$ [7].

\subsection{Factors affect walking speed}

Factors include door width, gender and body size are analysed subsequently.

\subsubsection{Door width}

One-way ANOVA was performed in order to test the difference of changing speed among seven door widths. It is found that changing speed at $0-2 \mathrm{~m}$. is not different but significantly different at $0.5-2 \mathrm{~m} .(\mathrm{p}=0.001)$ and $0-0.5 \mathrm{~m}$. $(\mathrm{p}=0.006)$.

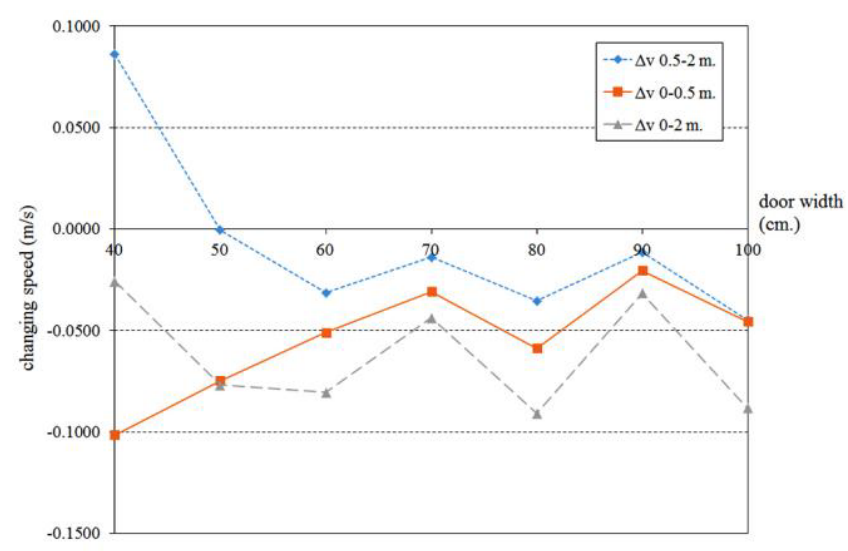

Figure 4. Main effects of door width.

As can be observed in Figure 4, changing speed at 0.5-2 m. seems to be different only at the door width of $40 \mathrm{~cm}$., consistent with the results obtained from post hoc test (Tukey's HSD test). Conversely, there is the direct variation between changing speed at $0-0.5 \mathrm{~m}$. and door width. This is comparable to Fitts' law. Additionally, linear relationship is found approximately at the door width of $40-70 \mathrm{~cm}$. 


\section{ICIEA 2016}
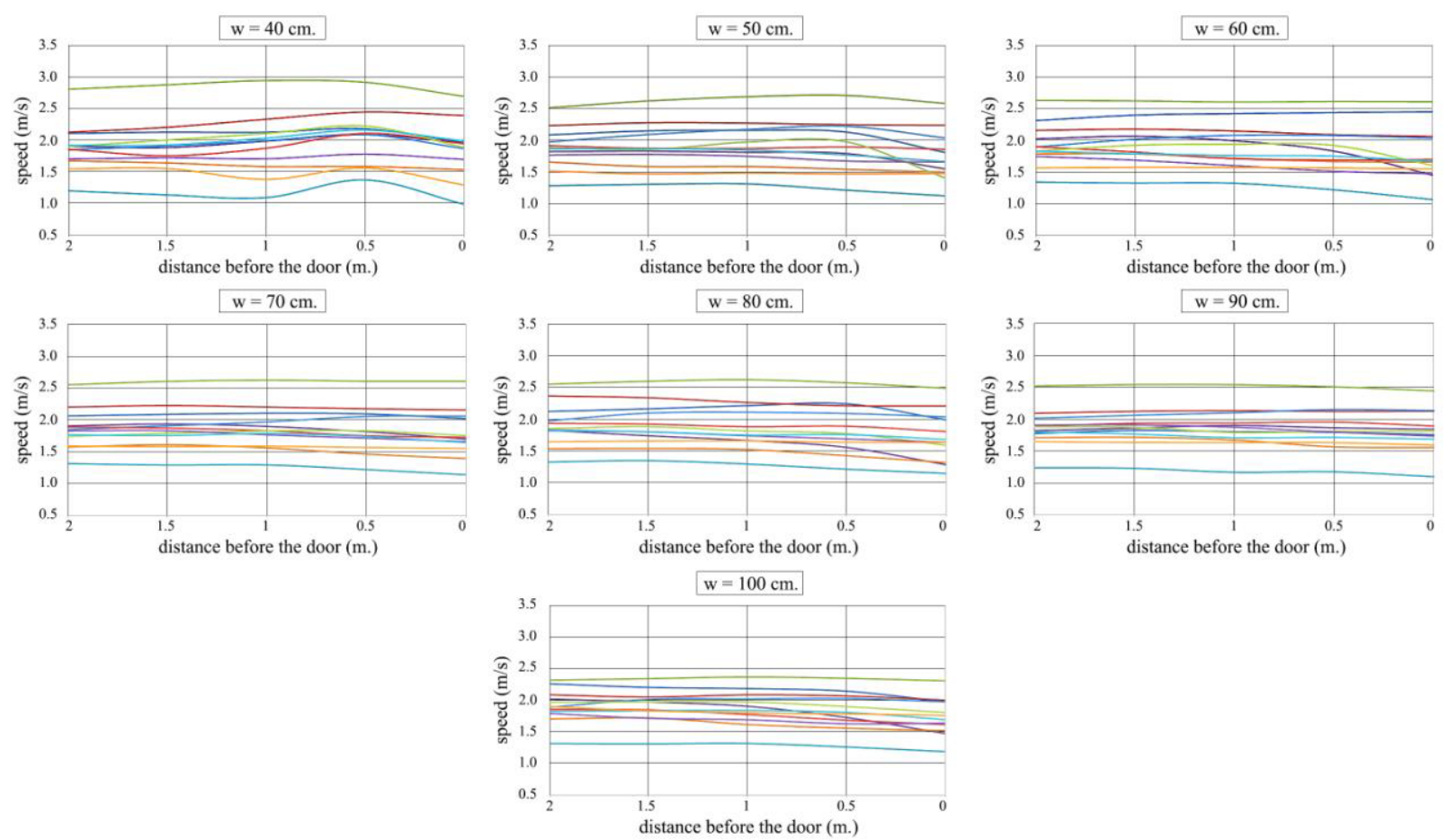

Figure 3. Walking speed along the distance of participants in group I, according to door width.

\subsubsection{Gender}

The independent sample t-test proved that there is no significant difference of changing speed between male and female. This probably due to the task was less risky. As a result, risk perception between male and female are not different. Other than that, the stimulus in this experiment did not appear unexpectedly so participant was able to notice and early beware. Ability of response between male and female are therefore similar.

\subsubsection{Body size}

Body size considered in this study consists of weight, height and body width that includes shoulder breadth and hip breadth. Changing speed at $0-0.5 \mathrm{~m}$. shows strong correlations with weight $(\mathrm{r}=-0.528, \mathrm{p}<0.001)$ and moderate correlations with shoulder breadth $(\mathrm{r}=-0.404, \mathrm{p}<0.001)$. No significant correlations between changing speed and hip breadth or height are observed. Although both shoulder breadth and hip breadth are considered in the interest of body width, hip breadth is always shorter and proximal among all participants. The effect of height is insignificant in this study due to the fixed height of door.

\subsection{Multiple regression analysis.}

After multiple regression analysis, shoulder breadth and weight are selected as the attributes of changing speed at 0$0.5 \mathrm{~m}$ before the door. Moreover, it is found that shoulder breadth highly correlates with weight $(\mathrm{r}=0.742, \mathrm{p}=0.006)$ Thus, interaction between shoulder breadth and weight is also significant. These factors explain $54.2 \%$ of this variable (See Table 2).

Table 2. Results of multiple linear regression analysis to predict changing speed at the door width of $40-70 \mathrm{~cm}$.

\begin{tabular}{|c|c|c|c|c|c|}
\hline & \multirow{2}{*}{ Coefficient $(\beta)$} & \multirow{2}{*}{ Standard error (S.E.) } & \multicolumn{2}{|c|}{ 95\% Confidence interval } & \multirow{2}{*}{$\mathrm{p}$-value } \\
\hline & & & Lower & Upper & \\
\hline Constant & -2.597 & 1.150 & -4.916 & -0.277 & 0.029 \\
\hline door width & 0.002 & 0.001 & 0.001 & 0.004 & $<0.001$ \\
\hline shoulder breadth & 0.062 & 0.027 & 0.008 & 0.117 & 0.026 \\
\hline weight & 0.041 & 0.019 & 0.003 & 0.078 & 0.035 \\
\hline shoulder breadth $\mathrm{x}$ weight & -0.001 & 0.000 & -0.002 & -0.000 & 0.021 \\
\hline
\end{tabular}

Changing speed in $\mathrm{m} / \mathrm{s}=-2.597+(0.002 \times$ door width $)+(0.062 \times$ shoulder breadth $)+(0.041 \times$ weight $)-(0.001 \times$ shoulder breadth $\mathrm{x}$ weight); $\mathrm{R}^{2}=0.542$.

\section{Conclusions}

From this study, it has found following conclusions.
In walking through the door, the speed reduction is found mostly at $0.5 \mathrm{~m}$. before the door. Walking behavior rather depends on weight. Participants with high weight reduce their walking speed when they are approaching the 
door that narrower than $70 \mathrm{~cm}$. Thus, the current standard door width around $80 \mathrm{~cm}$. is assigned properly.

Other than door width, human body size also affects to speed reduction. The changing speed presents weight-related decline as well as shoulder breadth. Since shoulder breadth associates with weight, interaction between shoulder breadth and weight is also significant.

For the future study, the investigation of other factors that can affect visual perception such as age would be conducted. Older or younger people may produce the difference in results. More complex situations such as increasing amount of people walking altogether or panic are also interesting.

\section{Acknowledgment}

The authors would like to thank all participants that willing participated in this experiment.

\section{References}

1. CFPA-Europe. Fire Safety Engineering Concerning Evacuation from Buildings (Milano, 2009)

2. E. D. Kuligowski, R. D. Peacock, B. L. Hoskins, A Review of Building Evacuation Models (2nd ed.) (NIST, Washington DC, 2010)

3. S. MacKenzie, Hum-Comput. Interact. 7, 91-139 (1992)

4. M. M. Samson, A. Crowe, P. L. de Vreede, J. A. G. Dessens, S. A. Duursma, H. J. J. Verhaar, Aging-Clin. Exp. Res. 13, 16-21 (2001)

5. D. K. Spierer, R. A. Petersen, K. Duffy, B. M. Corcoran, T. Rawls-Martin, J. Strength. Cond. Res. 24, 957-963 (2010)

6. C. R. Harris, M. Jenkins, Judg. Decis. Making. 1, 48-63 (2006)

7. International Code Council, Inc. International Building Code (Illinois, 2011) 